\title{
THE URINARY EXCRETION OF INSULIN BY NORMAL AND DIABETIC SUBJECTS ${ }^{1,2}$
}

\author{
BY I. ARTHUR MIRSKY, CLARENCE J. PODORE, JOHN WACHMAN, \\ AND ROBERT H. BROH-KAHN \\ (WITH THE TECHNICAL ASSISTANCE OF SUSAN BUCHER) \\ (From the May Institute for Medical Research, the Jewish Hospital, and the Department of \\ Internal Medicine, University of Cincinnati College of Medicine, Cincinnati)
}

(Received for publication April 14, 1948)

The fate of insulin injected into the blood stream is unknown. During the course of studies designed to investigate this problem, it became pertinent to inquire into the excretion of insulin from the body. Previous investigations on the urinary excretion of insulin have led to conflicting reports. Some studies $(1,2)$ have indicated that normal urine is capable of eliciting an hypoglycemic response which has been interpreted as proof of the presence of insulin in such urine. Other investigators $(3,4)$ have reported their inability to detect appreciable amounts of this hormone in the urine of man. In view of the controversial nature of such results and the need for more knowledge concerning the fate of injected insulin, it appeared advantageous to reinvestigate the problem of the urinary excretion of insulin.

The controversial results reported in the literature may be attributed partly to the technical difficulties involved in the estimation of a low concentration of insulin in a fluid menstruum such as urine. If urine contains very small quantities of insulin, then the equivalent of large volumes of urine would be required to produce a reliable hypoglycemic response. However the complex nature of urine and the presence of toxic substances may mask any hypoglycemic effect of the contained insulin by virtue of a toxic glycogenolytic effect. Accordingly the injection of crude urine cannot be utilized as a reliable procedure for the assay of insulin.

Cutting (4) attempted to circumvent this diffculty by precipitation of the insulin from urine with ammonium sulfate. She demonstrated that this procedure could be used effectively to recover 0.2 units of insulin from $100 \mathrm{ml}$. of urine but

\footnotetext{
1 Aided by grants from the New York Diabetes Association and the Eli Lilly Company.

2 Presented in part before the American Physiological Society, Atlantic City, March, 1948.
}

could not detect the presence of insulin in normal human urine with this procedure. Consequently she concluded that human urine must contain less than 0.2 units per $100 \mathrm{ml}$. If a normal individual excretes in the neighborhood of $1400 \mathrm{ml}$. of urine per day, such results would imply that less than 2.8 units of insulin are excreted each day. In order to detect such small quantities of insulin, it became necessary to devise a method adequate for this purpose. Accordingly, we have adopted for the estimation of the insulin content of human urine the following procedure which represents a modification of a method used in this laboratory for the preparation of urines for the extraction of other protein hormones excreted through the kidney.

\section{METHODS}

Specimens of urine were collected from each subject for periods varying from 24 to 120 hours. Every voided specimen was placed immediately in the refrigerator and kept in the cold until an entire day's collection had been obtained. Previous studies (4), confirmed by us, demonstrated no appreciable inactivation of insulin during this procedure. In order to remove the urinary salts, the 24-hour specimens were dialyzed overnight, against running ice cold water, in a Visking dialysis membrane. The dialyzed fluids were immediately shell frozen and desiccated by the lyophile process. The small amounts of dry powder obtained in this manner could be combined with similar dried products from the collection of urine on other days. The powders resulting from this procedure were fluffy, non-hygroscopic, easily handled and could be stored indefinitely without deterioration. If the urinary salts were not removed by dialysis prior to lyophilization, the resulting powders were hygroscopic, could be handled only with difficulty and could not be preserved in a stable form.

The average daily urine output of normal subjects was thus concentrated to a small quantity of the final dry product. The insulin in this small amount of solid material could be extracted by the same procedure as that which has been utilized for the assay of the insulin content of pancreatic tissue. Ten ml. of 70 per cent alcohol plus $0.03 \mathrm{ml}$. of concentrated sulfuric acid were added to 
each gram of powder. The mixture was stirred in a Waring Blender for five to ten minutes and centrifuged immediately. The residual undissolved material was reextracted in the same manner. The combined extracts were then concentrated in vacuo in order to reduce the volume, care being taken to insure that the acid concentration was not allowed to exceed 3 per cent during this process. Alcohol was added to the concentrated extract to a final concentration of 92 per cent. This was followed by the addition of 1.5 times this final volume of ethyl ether. The mixture was chilled and allowed to stand overnight in the cold room. The clear supernatant fluid was removed by decantation the following morning. The remaining precipitate was taken up in acid water and the residual traces of alcohol and ether removed in vacuo. The final acid water extract was made up to a definite volume and its insulin content determined immediately by the Young and Lewis (5) modification of the mouse assay.

For reasons which will be discussed below, it was found most feasible to perform urine insulin assays on specimens voided during 72 or more hours of collection. The analysis of such specimens revealed amounts of insulin ranging from 0 to 1.2 units; the mean quantity of insulin determined in such specimens being 0.48 units. It therefore appeared probable that a method capable of detecting the presence of from 0.4 to 0.5 units of insulin in urine could be considered valid for the purpose of this investigation.

To test the validity of the method of extraction and assay, from 0.4 to 0.5 units of insulin were added to urine which was then subjected to the entire process outlined above. A number of experiments demonstrated that the procedure detects small amounts of insulin. The results in Table I demonstrate recovery of from 60 to 100 per cent of 0.4 units of insulin added to the lyophilized powder obtained after dialysis of large volumes of urine. Furthermore, the addition of similar small amounts of insulin to urine prior to its dialysis revealed no appreciable loss of insulin during the process of dialysis. The results in Table I can be taken as indicative of the degree of the quantitative accuracy of our procedure for the determination of those amounts of insulin which were found to be excreted in urine. The results in this table also demon-

TABLE I

Recovery of insulin added to crude and lyophilized urine

\begin{tabular}{c|c|c|c|c}
\hline $\begin{array}{c}\text { Volume of } \\
\text { crude } \\
\text { urine }\end{array}$ & $\begin{array}{c}\text { Weight of } \\
\text { lyophilized } \\
\text { urine } \\
\text { powder }\end{array}$ & $\begin{array}{c}\text { Quantity } \\
\text { of insulin } \\
\text { added }\end{array}$ & $\begin{array}{c}\text { Quantity } \\
\text { of insulin } \\
\text { determined }\end{array}$ & $\begin{array}{c}\text { Recovery } \\
\text { of added } \\
\text { insulin }\end{array}$ \\
\hline $\begin{array}{c}\text { ml. } \\
1,000\end{array}$ & grams & $\begin{array}{l}\text { units } \\
0\end{array}$ & $\begin{array}{c}\text { units } \\
0.12\end{array}$ & per cent \\
1,000 & & 0.5 & 0.43 & 64 \\
\hline & 2 & 0 & 0.08 & \\
& 2 & 0.5 & 0.38 & 60 \\
\hline & 0.83 & 0 & 0.13 & \\
& 0.83 & 0.4 & 0.58 & 112 \\
\hline
\end{tabular}

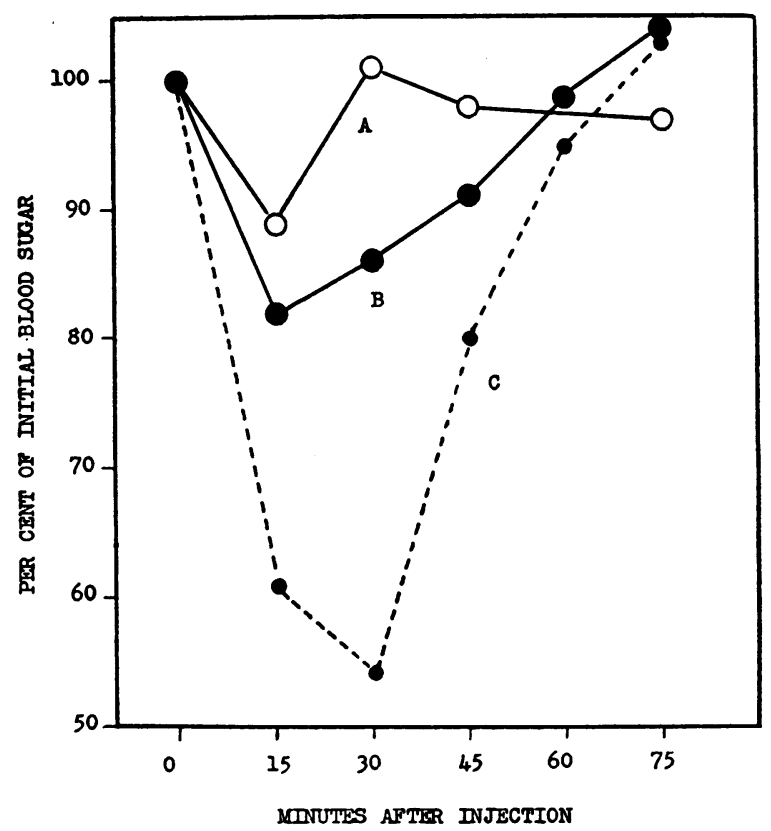

Fig. 1. Effect of Urine Extracts on the Blood Sugar OF THE RABBIT

A-Extract from 3 liters urine.

B-Extract from 5 grams urine powder.

C-Extract from 5 grams same urine powder to which 1 unit insulin had been added.

strate the fact that this method of analysis could detect the presence of the very small but appreciable amount of insulin excreted by normal subjects.

Although results obtained with the mouse convulsion assay and its various modifications are considered by convention specifically to detect the presence of insulin and although such assays have frequently been utilized to measure the insulin content of various organs and tissues, it is conceivable that the fall of the mice in the Young and Lewis assay might be due to factors other than insulin in the final acid saline extract. It therefore appeared advantageous to demonstrate that such extracts of urine actually contain a substance capable of producing a drop in the blood sugar of the rabbit. This was accomplished by the intravenous injection of the urine extracts into fasted rabbits and the determination of the degree of hypoglycemia produced. A typical protocol of such a procedure is found in Figure 1, which demonstrates that urine extracts actually do contain a substance which produces a fall in the blood sugar of rabbits.

Any substance of physiological origin which produces a transient hypoglycemia may be considered to be insulin. Furthermore, the degree of hypoglycemia produced in the rabbits corresponds roughly to the amount of insulin in such extracts as determined by the Young and Lewis mouse assay. Carefully controlled experiments of Cutting (4) demonstrated that a drop in the blood sugar of the rabbit of $25 \mathrm{mg}$. per cent corresponds to the presence of 0.2 units of insulin. 
Further proof of the similarity of the substance in urine extracts, responsible for the fall of mice in the Young and Lewis assay, and insulin was obtained by a comparison of the behavior of the two substances to heat. The results in Table II demonstrate that heating in a boiling water bath for one hour resulted in the abolition of the ability of both aqueous solutions of insulin and urine extracts to produce falls in mice in the Young and Lewis assay.

TABLE II

The effect of heating on the activity of urine extracts and insulin

\begin{tabular}{c|c|c|c}
\hline $\begin{array}{c}\text { Urine extract } \\
\text { assayed }\end{array}$ & $\begin{array}{c}\text { Insulin } \\
\text { added }\end{array}$ & $\begin{array}{c}\text { Exposure } \\
\text { to heat }\end{array}$ & $\begin{array}{c}\text { Units insulin } \\
\text { determined by } \\
\text { assay }\end{array}$ \\
\hline A & No & None & 0.4 \\
$A^{\prime}$ & No & $100^{\circ}$ C., 1 hr. & 0.1 \\
B & Yes & None & 0.7 \\
B $^{\prime}$ & Yes & $100^{\circ}$ C., 1 hr. & 0.1 \\
\hline
\end{tabular}

An acid saline extract was prepared from 4 grams of lyophilized urine powder as described in the text. The final extract was divided in four aliquots of $7.5 \mathrm{ml}$. each. $2.5 \mathrm{ml}$. of acid saline were added to each of two aliquots (A and $\mathrm{A}^{\prime}$ ). $2.5 \mathrm{ml}$. of a solution of insulin in acid saline containing $16 \mathrm{U} / 100 \mathrm{ml}$. were added to each of the other two aliquots ( $B$ and $\left.B^{\prime}\right)$. $A^{\prime}$ and $B^{\prime}$ were immersed for one hour in a boiling water bath and then cooled to room temperature and each restored to its original volume of $10 \mathrm{ml}$. The insulin content of each of the four solutions was then measured by the Young and Lewis mouse assay.

The results of these experiments, namely, the recovery of insulin added to urine before and after lyophilization, the hypoglycemic activity of urine extracts and their resemblance to insulin in regard to heat inactivation are believed to constitute strong presumptive evidence that the Young and Lewis assay actually detects and measures quantitatively the amount of insulin excreted in human urine.

\section{RESULTS}

Numerous assays of samples of urine collected for 24-hour periods revealed that normal subjects excrete minute but detectable amounts of insulin. However, in order to permit a comparison between individuals and between groups, it was deemed essential to prepare for assay extracts containing such amounts of insulin as would tend to increase the accuracy of the analytical procedure. Consequently, extracts were prepared from the combined lyophilized products of urine collections obtained over periods of from 72 to 120 . hours. The data obtained from such assays are presented in Figure 2 in which the absolute amount of insulin detected is expressed in terms of units excreted per 24 hours. The average daily insulin excretion of a group of 11 nondiabetic subjects was found to be 0.16 units with a standard deviation of \pm 0.04 units, with extremes of 0.10 to 0.24 units per day.

The insulin detected in the urine of these healthy subjects must have originated from endogenous sources since they received no exogenous supply. Therefore it appears obvious that only minute amounts of the insulin excreted by the pancreas ever escapes destruction (or utilization) within the body. It is conceivable that the rate of this insulin destruction might, in the healthy subject, just balance the rate of its pancreatic secretion. If such were the case, an exogenous supply of insulin might escape destruction and be excreted in the urine. In order to test this hypothesis several nondiabetic patients who were being subjected to shock therapy were given large amounts of insulin intravenously and the urine was collected at intervals thereafter and assayed for its insulin content. In no instance did this result in the recovery of more than infinitesimal fractions of the amount injected. Thus, in one instance, 400 units were given intravenously. From the urine voided during the first hour after injection 0.22 units were recovered, whereas 0.59 units were found in the urine excreted in the entire 24 hours after injection. This last quantity represents an increase of 0.43 units in excess of the mean daily excretion of the normal subjects considered in Figure 2. According to this calculation, only about 0.1 per cent of the amount of insulin injected was excreted within 24 hours. Such results have been typical of our failure to detect appreciable quantities of either endogenous or exogenous insulin in the urine.

In view of the fact that it is generally assumed that diabetic subjects suffer from an insulin insufficiency, it became pertinent to compare the insulin excretion of the diabetic patient with that of the apparently healthy subject. Although it would have been preferable to have utilized severely diabetic subjects for this purpose, such was not considered feasible since this would have necessitated the deprivation of insulin from such patients for 36 or more hours. Consequently, we studied the urinary excretion by a group of seven subjects whose metabolic disturbances were of such a degree of mildness that they did not require insulin for the regulation of their disease. The data obtained from these subjects are illustrated in Figure 2 which reveals that the average daily excretion of 


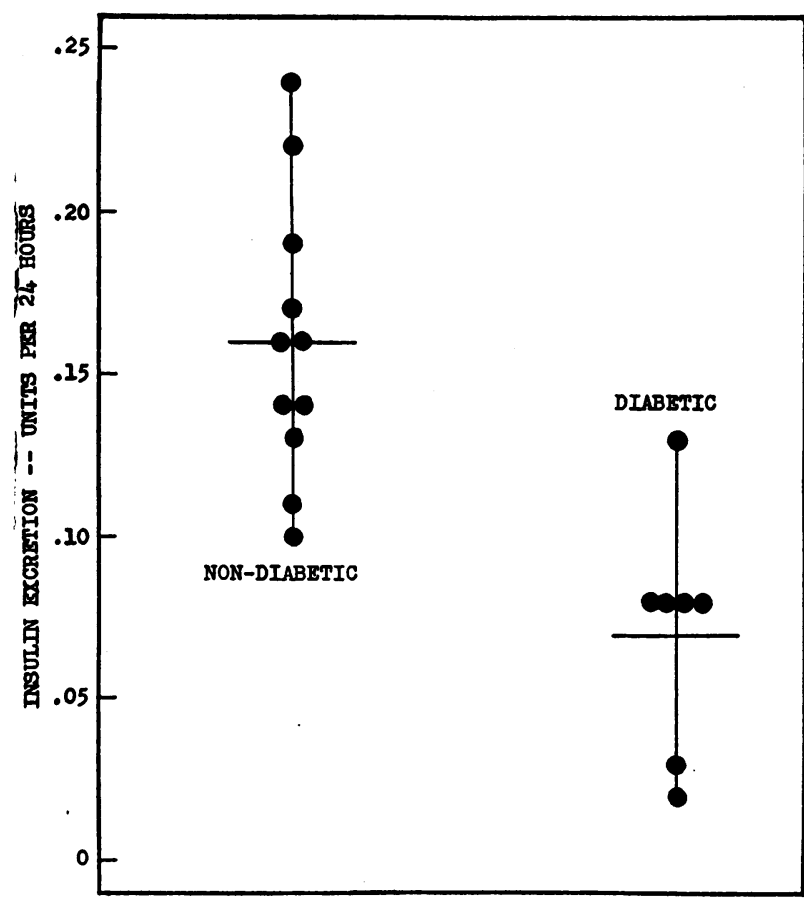

Fig. 2. Urinary Insulin Excretion by Non-Diabetic and Diabetic Subjects

The black circles indicate the excretion values of individual subjects. The horizontal lines indicate the mean insulin excretion per day for the respective groups.

these diabetic patients was 0.07 units with a standard deviation of 0.03 units, with extreme ranges of 0.02 and 0.13 units per day.

When urine was collected from a group of diabetic patients receiving insulin in quantities sufficient to control their metabolic disturbances, their insulin excretion per day was found to correspond to that observed in the non-diabetic subjects. Two diabetic patients with so-called "insulin resistance" were also studied. They excreted less insulin than did non-diabetic subjects to whom large amounts of exogenous insulin were administered. Thus, a 14 year old girl who required 240 units daily for the regulation of her diabetes excreted 0.2 units per day. Another patient, who required 350 units per day, excreted 0.3 units per 24 hours. Such values were significantly lower than the 0.6 units excreted after the injection of 400 units into the non-diabetic subject.

\section{DISCUSSION}

It has been postulated by many clinicians that the administration of insulin in multiple divided doses might be more economical than the adminis- tration of a similar amount in a single dose. This claim has been based on the assumption that an appreciable fraction of the single dose of insulin might be excreted more rapidly than it could be used within the body. Our results fail to substantiate such an assumption since we find that only infinitesimal fractions of even tremendous doses of insulin are ever excreted in the urine. Presumably, therefore, wastage of insulin as a result of its excretion is of no practical consideration.

The average daily excretion of normal subjects was found to be $0.16 \pm 0.04$ units per day; the average excretion of patients with diabetes mellitus was found to be $0.07 \pm 0.03$. The difference between the means of the two groups is 5.6 times greater than the standard error of their difference, thus indicating a statistically significant difference in the insulin excretion of the two groups. In view of the very small difference in the absolute amount of insulin excreted by the two groups, it cannot be stated conclusively that the average mild diabetic patient is characterized by a lower insulin excretion than the normal subject. Nevertheless such differences do lend support to the hypothesis that the diabetic patient suffers from an insulin insufficiency.

Of greater significance than the preceding is the fact that normal as well as diabetic subjects excrete minute quantities of insulin irrespective of whether or not large amounts of exogenous insulin are administered. The fate of endogenous and exogenous insulin remains unknown but our data do warrant the assumption that insulin undergoes rapid destruction within the body.

\section{SUMMARY AND CONCLUSIONS}

1. A method is described for the assay of insulin excreted in the urine by man.

2. The daily insulin excretion was determined in normal and diabetic subjects some of whom received exogenous insulin.

3. The average daily excretion by normal subjects was $0.16 \pm 0.04$ units per day. The average excretion by mildly diabetic subjects who did not require insulin for the regulation of their disease was $0.07 \pm 0.03$ units per day. This difference was found to be statistically significant.

4. Only minute fractions of large amounts of exogenous insulin were excreted by either normal subjects or patients with diabetes mellitus. 
5. Insulin-resistant patients who received large amounts of insulin appeared to excrete a smaller amount of exogenous insulin than did normal subjects also receiving large amounts of insulin.

6. The data warrant the assumption that insulin undergoes a rapid destruction within the body.

\section{BIBLIOGRAPHY}

1. Partos, A., Regulation des Kohlenhydratstoff wechsels; Ausscheidung des Insulins durch die Nieren und ihre Bedingungen. Arch. f. d. ges. Physiol., 1929, 221, 562.

2. Brugsch, H., and Horsters, H., Insulin im Harn. Arch. f. exper. Path. u. Pharmakol., 1930, 148, 309.

3. Lawrence, R. D., Madders, K., and Millar, H. R., Excretion of insulin in urine. Brit. J. Exper. Path., 1930, 11, 117.

4. Cutting, M., The detection of insulin in urine. Biochem. J., 1942, 36, 376.

5. Young, D. M., and Lewis, A. H., Detection of hypoglycemic reactions in the mouse assay for insulin. Science, 1947, 105, 368.

\section{LETTER FROM THE EDITORS}

At times it is the duty of editors to call attention to practices in the writing of scientific papers which indicate either a grave lapse from.literary etiquette or a cloudy concept of intellectual honesty. We refer to the practice of lifting ideas or even large portions of text from previously published articles with no hint of the source and no acknowledgment. Such plagiarism may consist of borrowing paragraphs and pages or copying a bibliography intact with errors and all. We have had papers submitted parts of which were directly copied from readily available medical journals, or the changes made were so slight as to be inconsequential. While the original author may feel flattered to have his ideas accepted so utterly, the filcher will be found out soon or late to his sorrow and the embarrassment of his editors.

Scientific data and clinical observations are not the proprietary right of those who gather and record them. They are published for such general use as may be appropriate. It is a great solace to one doing research to have his own work approved and accepted by others. This is a legitimate reward. A passion for anonymity does not haunt investigators. It is proper that recognition be given those who toil to advance the fronts of knowledge and provide a basis for wisdom. This custom has a long and honored tradition. It was practiced by Aristotle who went to great pains to give credit by name and reference to those whose work he sought to integrate and interpret.

We are not concerned with the legal aspects of patent laws or those which deal with plagiarism. We are concerned with the moral and ethical implications of a writer trying to take credit for the work of somebody else. Honesty cannot be compartmentalized and one looks askance on the data presented in such a background.

Progress in investigation is of necessity a derivative process and it has been remarked that scientists stand on the shoulders of those who have gone before. Science is a mosaic in which new pieces must be fitted against the old. Similar ideas may occur independently and simultaneously to widely separated workers whose factual data and thought processes follow a common path. We are not worried about dead heats in the races for priority. When papers are accepted for publication the proviso is usually attached that the same material is not sent to other journals. To this we would add the proviso that credit be given where credit is due and that medical writers avoid the temptation to borrow someone else's work. 